\title{
Appropriate advertising in dentistry: Where is the line in the sand?
}

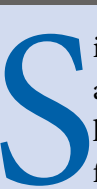

ir, traditionally, dentists might have advertised their practices in the local paper, Yellow Pages or using flyers, but with an ever-growing online platform and around one million new internet users every single day worldwide ${ }^{1}$ as well as the emergence of social media in the form of Facebook and Instagram, onlinemarketing has become the new cornerstone of dental advertising. Irrespective of the channel utilised to promote dental services, the UK has strict regulations in place when it comes to advertising. According to the Dental Defence Union, dental professionals are obligated to 'advertise in accordance with standards set out by the Advertising Standards Authority (ASA) and the Committee of Advertising Practice (CAP)'.2 Additionally, any promotional content published needs to comply with the General Dental Council's guidance on ethical advertisement. ${ }^{3}$

In modern dentistry, many patients no longer only seek treatment of disease but rather improvements of aesthetics, ${ }^{4}$ and many are seeing cosmetic dentists to obtain their dream smile. A 2019 survey showed that $43 \%$ of UK respondents were looking to improve their smile using cosmetic procedures such as whitening, veneers or Invisalign. ${ }^{5}$ The promotion of such dental services, also known as dental advertising, is the key to success for many dental practices and practitioners to obtain their share of the profit from an industry worth around $£ 3.6$ billion per year in the UK. ${ }^{6}$ Advertising on social platforms has become increasingly popular and offers the advantage of being able to reach a wider audience as well as targeting specific groups of people. In 2018, Parmar et al found that more than $55 \%$ of dentists have a social media presence related to their dental practice, ${ }^{7}$ used to promote their work and create a following. Considering that the pandemic has led to screen-time increases of several hours per day across all age groups, ${ }^{8}$ social media presence is becoming more and more important to promote brands and services including dental and facial aesthetic treatments such as Botox and dermal fillers. Many posts are now sponsored meaning that healthcare professionals will promote and endorse certain products in return for a financial reward. This practice clearly raises numerous ethical issues which have been explored in detail.

The commercialisation of oral healthcare seen in recent years has started to blur the lines when it comes to ethical advertising, particularly in the field of cosmetic dentistry. It is of utmost importance to uphold advertising standards as dentists become more and more business-focused. Advertising has the potential to shift social norms with respect to dental appearance and concerns have been raised whether ethical and professional standards can be upheld. As a profession we are now standing at the crossroads; our actions or inactions at this point with regards to the promotion of the so-called 'perfect smile' will pave the path for the future of dentistry and what it stands for within society. We need to take a stronger stance and advise patients that aesthetic treatments may not necessarily be in their best interest and that a natural smile can be just as desirable as straight white teeth.

S. Butzin, Preston, via email

\section{References}

1. ClickZ. Internet growth + usage stats 2019: Time online, devices, users. 2019. Available online at: www.clickz.com/internet-growth usage-stats-2019-time-online-devicesusers/235102/ (accessed 9 November 2021).

2. Dental Defence Union. Advertising your practice ethically - The DDU. Available online at: www.theddu.com/guidance-and-advice/ guides/advertising-your-practice-ethically (accessed 7 December 2021).

3. General Dental Council. Guidance on advertising. 2013

4. Dental Protection. Cosmetic dentistry: ethics and aesthetics. Available online at: www. dentalprotection.org/uk/articles/cosmeticdentistry-ethics-and-aesthetics-uk (accessed 9 November 2021).

5. Dentistry.co.uk. UK survey says $43 \%$ of respondents want whitening, veneers or straighter teeth. January 2019. Available online at: https://dentistry.co.uk/2019/01/04/uk-surveysays-43-respondents-want-whitening-veneersstraighter-teeth/ (accessed 9 November 2021)

6. IBISWorld. Dental Practices in the UK - Industry Data, Trends, Stats. 2020. Available online at: www.ibisworld.com/united-kingdom/marketresearch-reports/dental-practices-industry/ (accessed 9 November 2021).

7. Parmar N, Eisingerich A B, Dong L. Connecting with your dentist on Facebook: Patients' and dentists' attitudes towards social media usage in dentistry. J Med Internet Res 2018; 20: e10109.

8. Nagata J M, Cortez C A, Cattle C J, et al. Screen time use among us adolescents during the COVID-19 pandemic: findings from the adolescent brain cognitive development (ABCD) study. JAMA Pediatr 2022; 176: 94-96.

\section{Leadership in dentistry}

Sir, I read with great interest the paper by Janine Brooks MBE, on intelligent leadership and leadership skills. ${ }^{1}$

In dentistry it is often mooted that Leadership skills are essential, but in many circumstances obtaining them practically can be a challenge. This paper provided a structured, thoughtful, inspirational approach, applying this perfectly to dentistry.

As somebody involved in Dental Education some sections really resonated in developing Leadership skills across the dental team - '360 multi-source feedback is a useful tool for constructive, developmental feedback.

In my experience this works best when team members are advised that this is not others judging, but allowing you the chance to see things from the perspective of another team member ie what is the nurse seeing that you are not? Why does the technician feel your communication skills are poor, but you don't? This perspective, may well be different to your own, but can be far more constructive in developing your skills rather than a debate on who is right or wrong. Creating a safe space for feedback and discussion is essential.

Similarly I thought the section on Integrity had so much value for the whole dental team.

'Integrity melds together honesty and ethical behaviour' and 'It's about doing the right thing even if it's not in your personal interest?

This section highlighted the importance of leadership skills and the close relationship to professionalism when one considers doing the right thing particularly when things go wrong, much as suggested in the Professional Duty of Candour. ${ }^{2}$

There was so much in this article that was inspirational, informative, and in my opinion essential reading no matter the stage of your career.

E. McColl, Director of Clinical Dentistry, Peninsula Dental School, Plymouth, UK

\section{References}

1. Brooks, J. Intelligent leadership and leadership skills. BDJ In Pract 2022; 35: 16-18.

2. General Dental Council. The Professional Duty of Candour. Available online at: www. gdc-uk.org/information-standards-guidance/ standards-and-guidance/gdc-guidance-fordental-professionals/the-professional-dutyof-candour (Accessed January 2022). 